\title{
Self harm and the emergency department
}

\author{
Clinicians' reactions to people who self harm can make all the difference. For series information \\ contact Rosamund Snow, patient editor, rsnow@bmj.com. The author can be contacted on Twitter \\ under the handle @DrEm_79
}

\section{twitter DrEm_79}

I speak quietly at the emergency department reception desk, but much of the waiting room can still hear. There isn't an easy way to announce in a room full of strangers that you've hurt yourself, again. In case anyone listening is in doubt, then comes the question: "Did you do this to yourself?"

Self harm is one of the most common reasons for general hospital admission. ${ }^{12}$ People who present to the emergency department with self harm have a relative risk of suicide 49 times greater than the general population, ${ }^{3}$ and up to 100 times greater in the next year.

Emergency department clinicians have saved my life more than once. But self harm often comes with stigma, and our interactions are uneasy. I'm a "frequent flyer" (their term) and can be met with extremes. From the most thoughtful, compassionate care to frustration, blame, judgment, and shaming.

I don't expect the emergency department at 3 am to provide a solution-I've been self harming for 30 years and there isn't a quick fix-but there are things you can do to help. Ensuring that the cause of the injury doesn't affect the quality of care is important. When I self harm, my injures are serious-yet I'm rarely offered analgesia. Offering analgesia shows that you think the person does not deserve to hurt. I've sometimes heard, "but I thought you liked pain," and been told how expensive dressings are.

\section{Small things can help}

Many people who self harm have experienced trauma. Healthcare environments can trigger associations with that trauma and be frightening. If the person is able to tell you, ask what would help them to feel safe-for example, not being made to wear a gown unless it is clinically essential, or being offered the opportunity to sit on a chair rather than a trolley or bed.

Self harm can help some people find control in a desperate situation where there is none, so it's important not to take more control away from them or to dismiss them. For example, I was told by clinicians that there is "no point in seeing me" if I am "refusing treatment" when I was too fearful to accept admission by the plastics team; but I could have managed dressings, emergency wound care, and outpatient review if it had been offered. I appreciate being offered gold standard treatment, but if sometimes I cannot accept parts of it please don't walk away. Work with me to find the best treatment I can tolerate.

\section{Self harm is often a private act}

Even though self harm has led to many hospital admissions, including time in intensive care, few of my work colleagues, friends, or family know. For some people, the emergency department is the only place where their injuries will be seen by another person. Think about what each stage of the assessment and treatment process requires of the person and the impact it might have. Maximise privacy where you can, closing curtains during examination, and replacing temporary dressings after triage.

There are as many reasons for self harming as people who self harm, but a common theme is that it stems from a place where there is psychological pain. So making people feel worse about what they've done is unlikely to make them stop self harming. It may increase the risk of repetition or stop people seeking help.

By contrast, people who treat me with dignity and compassion help me more than they realise.

Self harm can be a way to try to find control, so it's important you avoid taking more control away

Competing interests: I have read and understood BMJ policy on declaration of interests and declare the following interests: none.

National Institute for Health and Care Excellence. Quality standard for self-harm. http:// www.nice.org.uk/guidance/QS34/chapter/Introduction-and-overview. 2013.

2 Royal College of Psychiatrists. Better services for people who self-harm- Quality standards for healthcare professionals. 2006. http://www.rcpsych.ac.uk/PDF/Self-Harm\%20Quality\% 20Standards.pdf.

3 Hawton $\mathrm{K}$, Bergen $\mathrm{H}$, Cooper $\mathrm{J}$, et al. Suicide following self-harm: findings from the Multicentre Study of self-harm in England, 2000-2012. J Affect Disord 2015;175:147-51. doi:10.1016/j.jad.2014.12.062. pmid:25617686.

Published by the BMJ Publishing Group Limited. For permission to use (where not already granted under a licence) please go to http://group.bmj.com/group/rights-licensing/ permissions 


\section{What you should know}

- Don't let the cause or frequency of harm affect care; assess pain and offer analgesia

- Avoid "all or nothing" approaches, where turning down suggested treatment means being turned away

- A lack of control can contribute to self harm; involve patients in decisions and facilitate self care 